\title{
Modern health-seeking behaviour and associated factors among mothers having under 5-years old children in Shire town, Tigray, Ethiopia: A cross-sectional study 2018
}

\begin{tabular}{|c|c|}
\hline \multicolumn{2}{|c|}{ 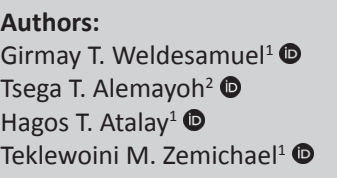 } \\
\hline \multicolumn{2}{|c|}{$\begin{array}{l}\text { Affiliations: } \\
\text { 'School of Nursing, Aksum } \\
\text { University, Aksum, Tigray, } \\
\text { Ethiopia }\end{array}$} \\
\hline \multicolumn{2}{|c|}{$\begin{array}{l}\text { 2Department of Medical } \\
\text { Laboratory, Aksum University, } \\
\text { Aksum, Tigray, Ethiopia }\end{array}$} \\
\hline \multicolumn{2}{|c|}{$\begin{array}{l}\text { Corresponding author: } \\
\text { Girmay Weldesamuel, } \\
\text { girmeat@gmail.com }\end{array}$} \\
\hline $\begin{array}{l}\text { Dates: } \\
\text { Received: } 14 \\
\text { Accepted: } 23 \\
\text { Published: } 21\end{array}$ & $\begin{array}{l}\text { Aug. } 2018 \\
\text { May } 2019 \\
\text { Aug. } 2019\end{array}$ \\
\hline \multicolumn{2}{|c|}{$\begin{array}{l}\text { How to cite this article: } \\
\text { Weldesamuel GT, Alemayoh } \\
\text { TT, Atalay HT, Zemichael TM. } \\
\text { Modern health-seeking } \\
\text { behaviour and associated } \\
\text { factors among mothers } \\
\text { having under 5-years old } \\
\text { children in Shire town, Tigray, } \\
\text { Ethiopia: A cross-sectional } \\
\text { study 2018. Afr J Prm Health } \\
\text { Care Fam Med. 2019;11(1), } \\
\text { a1913. https://doi.org/ } \\
\text { 10.4102/phcfm.v11i1.1913 }\end{array}$} \\
\hline \multicolumn{2}{|c|}{$\begin{array}{l}\text { Copyright: } \\
\text { (C) 2019. The Authors. } \\
\text { Licensee: AOSIS. This } \\
\text { is licensed under the } \\
\text { Creative Commons } \\
\text { Attribution License. }\end{array}$} \\
\hline \multicolumn{2}{|l|}{ Read online: } \\
\hline 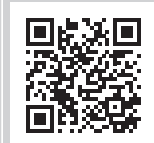 & $\begin{array}{l}\text { Scan this QR } \\
\text { code with your } \\
\text { smart phone or } \\
\text { mobile device } \\
\text { to read online. }\end{array}$ \\
\hline
\end{tabular}

\begin{abstract}
Background: The practice of appropriate health care-seeking is important to reduce severe and life-threatening childhood illnesses. In Shire town, little is known about the mother's health care-seeking behaviour on childhood illness.
\end{abstract}

Aim: To assess modern health-seeking behaviour and associated factors of mothers having under 5-years old children in Shire town.

Setting: The study setting was Shire town, northwest Tigray, Ethiopia.

Methods: A community-based cross-sectional study was conducted to interview 504 motherchild pairs by systematic random sampling technique. Data were collected through intervieweradministered semi-structured questionnaires. Data were coded, entered, cleaned and edited using EPIDATA version 3.1 and export to Statistical Package for Social Science (SPSS) Version 22.0 for analysis. To identify the significant variables, binary logistic regression was employed. Variables with $p$-value $<0.05$ at 95\% CI (confidence interval) in multivariate logistic regression were considered statistically significant.

Results: In this study, around $76.2 \%(72.1,80)$ of mothers sought modern health care. In a multivariate logistic regression analysis at a $p$-value of $<0.05$, caregivers with age of $\geq 28$ years (AOR [adjusted odds ratios]: 1.65; 95\% CI [1.02, 2.68]), educational level of secondary school and above (AOR: $0.44 ; 95 \%$ CI $[0.23,0.86]$ ), child feeding per day $<8$ times (AOR: $2.77 ; 95 \%$ CI $[1.75,4.38]$ ) and perceived severity of illness (AOR: 2; 95\% CI [1.07, 3.82]) were statistically associated with modern health care-seeking behaviour.

Conclusion: Strengthen healthcare services is recommended at the community level through information, education and communication/behavioural change strategies to improve the mother's health care-seeking behaviour.

Keywords: modern; health care-seeking behaviour; under 5-years old children; mother.

\section{Background}

Health care-seeking behaviour is an action taken by an individual to an internal and external stimulus to find a suitable solution after the child has a health problem. ${ }^{1}$ According to the World Health Organization (WHO), human health is complete physical, mental and social well-being not merely the absence of disease..$^{2,3,4}$

Childhood illnesses are the main health problems globally, predominantly in Asian and African subcontinents. ${ }^{5}$ Around 6.3 million children aged under 5 years died in 2013 worldwide, which could be prevented with simple and inexpensive interventions. ${ }^{6}$ This is the most vulnerable group of the population suffering from common childhood illness. ${ }^{6}$ The global under-five mortality in 2013 was 41 per 1000 live births ${ }^{6}$ and 67 deaths per 1000 live births in Ethiopia in 2016. ${ }^{7}$

The children are at risk for malnutrition because of the problems in nutrition, socio-economic and health factors. ${ }^{8}$ Delay in proper care of mothers in modern health facilities is a major cause of child death all over the world especially in sub-Saharan Africa. ${ }^{9,10}$ Furthermore, poverty and lack of education are the major factors associated with under-five mortality in Ethiopia. ${ }^{7}$

According to the WHO, child mortality and morbidity could be reduced by $20 \%$ if there is appropriate health-seeking behaviour. ${ }^{11}$ Health-seeking behaviour is a function of not only the 
accessibility of health facilities and other sources of health care but also inspiration and capacity of individuals to seek medical treatment. ${ }^{12}$

Even though the common childhood illnesses are manageable successfully if timely recognised, facilitation of modern careseeking behaviour remains a challenge today. ${ }^{13}$ A large number of children die without ever reaching a health facility. ${ }^{10}$ This is attributed to delays in seeking care by mothers. ${ }^{10}$ This delay affects child health and leads to child health complications that make medical care to be ineffective. Therefore, appropriate care-seeking behaviour is an important parenting instrument in preventing the child from preventable morbidity and moralities. ${ }^{14}$

To meet the Sustainable Development Goal (SDG) target one on under-five mortality by 2030 in reducing the number of under- 5 deaths by 10 million between 2017 and 2030, ${ }^{5}$ rapid improvement is needed to raise the community awareness in modern health-seeking behaviour.

Although Ethiopia has universal access improvement on standard management of common childhood illnesses, ${ }^{15}$ modern care-seeking behaviour of caregivers for childhood illness remained low. In Shire town, the modern healthseeking behaviour and the associated factors remained unclear and insufficiently studied. Therefore, the aim of this study is to assess modern health-seeking behaviour and associated factors among mothers who have children under the age of five years in Shire town, Northwest Tigray, Ethiopia.

\section{Methods}

\section{Study area}

The study was conducted from March to April 2018. Shire town is located $1087 \mathrm{~km}$ from Addis Ababa, the national capital city of Ethiopia and $309 \mathrm{~km}$ from Mekelle, the regional capital city of Tigray. The town has two governmental hospitals, two governmental health care centres, and one private health care centre. According to the 2007 population census, the total population of Shire town was approximately 47284.

\section{Study design}

The community-based, cross-sectional study design was employed.

\section{Study populations}

All mothers who have children under the age of five years in Shire town were the source population and who have children under the age of five years at randomly selected Kebeles (the smallest administrative unit in Ethiopia) was the study population and sampled mothers in the selected Kebeles (the smallest administrative unit in Ethiopia) were the study units. Mothers who are seriously ill, mentally ill and unable to speak and listen were excluded from the study. In this study, the dependent variable was modern health care-seeking behaviour for common childhood illness and the independent variables were sociodemographic factors, childhood factors, and service availability and accessibility.

\section{Sample size and sampling technique}

The sample size was determined using single population proportion determination formula by taking the magnitude of health-seeking behaviour $72.7 \%$ from previous studies conducted in Bahir dar, ${ }^{16}$ 5\% marginal error (d) with 95\% confidence. The final sample size with the design effect of 1.5 and $10 \%$ non-response rate was 504. Multi-stage sampling technique was used for interviewing 504 study participants.

From the total five Kebeles, three Kebeles were selected by simple random sampling technique. To get the sample size from these three Kebeles (the smallest administrative unit in Ethiopia) proportional allocation to sample size was carried out. Then systematic sampling technique $(K=16)$ was used to choose the household for an interview. The first mother was selected using a lottery method. The household numbers were taken from health extension workers in Shire town a sampling frame was made from it.

\section{Data collection tools and procedure}

Three nurses with a BSc degree collected data using a pretested interviewer-administered structured questionnaire. The tools were adapted from different works of literature ${ }^{13,16,17,18}$ then modified and rewritten to fit the local situation and research objective. To minimise errors in data entry double data entry was applied.

\section{Operational definition}

\section{Modern health care-seeking behaviour}

Mothers/caregivers of sick children going to formal health care institutions (government health facilities and private hospitals/clinics) to seek care. ${ }^{2}$

\section{Caregiver}

The responsible individuals who take care of a child either the relatives of the child or the mother. ${ }^{13}$

\section{Data quality control}

The training was given to data collectors regarding the objective of the study and data collection methods. The questionnaire was prepared in English then translated into Tigrigna (local language). The tool was pre-tested on $5 \%$ of the sample size in Aksum town. Continuous follow-up and supervision were made by the supervisor and principal investigator to check for completeness and consistency of the data.

\section{Data processing and analysis}

The data were coded, entered, cleaned and edited using EPIDATA version 3.1, and then exported to Statistical 
Package for Social Science (SPSS) Version 22.0 for analysis. A binary logistic regression model was used to look at the statistical association between the outcome variable and every single independent variable. Variables that showed statistical significance during bivariate analysis at $\leq 20 \%$ $(p$-value $\leq 0.20)$ were entered into multivariate logistic regression by using the backward elimination method. The appropriateness of the model for analysis was checked by the Hosmer-Lemeshow test. Results were shown using tables and texts. The strength of associations was estimated by using adjusted odds ratios (AOR) with 95\% CI and significance were declared at a $p$-value $<0.05$.

\section{Ethical considerations}

Ethical clearance was obtained from Aksum University, College of Health Science, Institutional Review Board (AKU-CHS, IRB) of the research committee. Official permission was also secured from the Tigray Regional Health Bureau. Then a permission and support letter was written to the health office of Aksum town. Respondents were informed about the purpose of the study, the information was collected after obtaining written consent from each participant. Written consent from all the informed respondents were needed before the start of each interview. Respondents were allowed to refuse or discontinue participation at any time they wanted. Information was recorded anonymously and confidentiality and beneficence were assured throughout the study.

\section{Results}

\section{Sociodemographic characteristics of mothers or caregivers and children}

About 504 mothers/caregivers were involved with the response completion rate of $100 \%$. The majority of study participants, 492 (97.6\%) were biological mothers of the child, 297 (59\%) were equal to or over 28-years old and 294 (58.3\%) were Orthodox Christians. In this study, 449 (88.9\%) mothers / caregivers were married and 193 (38.3\%) were housewives by occupation. Regarding the educational status, 167 (33.1) of the mothers and/or caregivers were in primary school (1st-8th Grade) and around $336(66.7 \%)$ had less than or equal to five family members. Around 260 (51.6\%) mothers/ caregivers wanted a girl child. With regard to the children, $153(30.4 \%)$ were in the age group of $0-11$ months and the sex of the child was evenly distributed between female and male (Table 1).

\section{Health-seeking behaviour and health service utilisation of mothers in Shire town}

In this study, $357(70.8 \%)$ mothers were having greater than four antenatal care (ANC) follow-ups and 489 (97\%) gave birth in health facilities. Around 335 (66.5\%) children were exclusively breastfed for more than eight times (Table 2).

Overall, around 489 (97\%) caregivers were facing one or more childhood illness and the common childhood illnesses complained by mothers were cough 261 (53.4\%), fever $203(41.5 \%)$ and diarrhoea 128 (26.2\%). With respect to
TABLE 1: Sociodemographic characteristics of mothers/caregivers, and child in Shire Town, Tigray, Ethiopia, 2018.

\begin{tabular}{|c|c|c|}
\hline Variables & Frequency & Percentage \\
\hline \multicolumn{3}{|l|}{ Primary caregiver of child } \\
\hline Mother & 492 & 97.6 \\
\hline Out of mother & 12 & 2.4 \\
\hline \multicolumn{3}{|l|}{ Age } \\
\hline$<27$ years & 207 & 41.1 \\
\hline$\geq 28$ years & 297 & 58.9 \\
\hline \multicolumn{3}{|l|}{ Marital status } \\
\hline Married & 449 & 89.1 \\
\hline Divorced & 45 & 8.9 \\
\hline Widowed & 10 & 2.0 \\
\hline \multicolumn{3}{|l|}{ Occupation } \\
\hline Farmer & 34 & 6.7 \\
\hline Governmental labour & 147 & 29.2 \\
\hline Merchant & 87 & 17.3 \\
\hline Daily labour & 43 & 8.5 \\
\hline Housewife & 193 & 38.3 \\
\hline \multicolumn{3}{|l|}{ Religion } \\
\hline Orthodox & 294 & 58.3 \\
\hline Protestant & 75 & 14.9 \\
\hline Muslim & 126 & 25.0 \\
\hline Other & 9 & 1.8 \\
\hline \multicolumn{3}{|l|}{ Educational status } \\
\hline Unable to read and write & 60 & 11.9 \\
\hline Primary school & 167 & 33.1 \\
\hline Secondary school & 154 & 30.6 \\
\hline College and above & 123 & 24.4 \\
\hline \multicolumn{3}{|l|}{ Number of families } \\
\hline$<5$ & 336 & 66.7 \\
\hline$\geq 5$ & 168 & 33.3 \\
\hline \multicolumn{3}{|l|}{ Age of child } \\
\hline 0-11 months & 153 & 30.4 \\
\hline $12-23$ months & 102 & 20.2 \\
\hline 24-35 months & 105 & 20.8 \\
\hline 36-47 months & 54 & 10.7 \\
\hline 48-59 months & 90 & 17.9 \\
\hline \multicolumn{3}{|l|}{ Family preferred sex } \\
\hline Male & 164 & 32.5 \\
\hline Female & 142 & 28.2 \\
\hline Both & 198 & 39.3 \\
\hline \multicolumn{3}{|l|}{ Sex of child } \\
\hline Male & 244 & 48.4 \\
\hline Female & 260 & 51.6 \\
\hline
\end{tabular}

TABLE 2: Markers of modern health care-seeking behaviour associations in Shire town, North Ethiopia, $2018(n=504)$.

\begin{tabular}{lcc}
\hline Variables & Frequency & Percentage \\
\hline ANC follow-up & 147 & 29.2 \\
$<4$ times & 357 & 70.8 \\
$\geq 4$ times & & \\
Maternal delivery & 489 & 97.0 \\
Health institution & 15 & 3.0 \\
Home & & \\
Breastfeeding per day & 169 & 33.5 \\
$<8$ times & 256 & 50.8 \\
$\geq 8$ times & & \\
Duration of EBF & 169 & 33.5 \\
$<6$ months & 335 & 66.5 \\
$\geq 6$ months &
\end{tabular}

ANC, antenatal care; EBF, exclusive breastfeeding. 
decision-making regarding the health of the child, mothers made $358(71.0 \%)$ decisions. Overall, the magnitude of modern health care-seeking behaviour of mothers was $76.2 \%$ $(72.1,80)$. The main reason for those who did not seek medical care was stated as being the cost of medical care (41.2\%) and perceived as perceived as a mild illness (29.4\%). Around 103 $(20.4 \%)$ of the caregivers delayed seeking modern health care for $\geq 3$ days. The main reason for this was 'thought the illness was mild/will resolve by itself'. Regarding the perception of illness, nearly half $236(46.9 \%)$ of mothers perceived that the illness of their child was mild and around $283(56.2 \%)$ mothers identified the severity of illness by viewing different symptoms (Table 3 ).

\section{Factors associated with modern health care- seeking behaviour of mothers in Shire town}

In the binary logistic regression at a $p$-value of $\leq 0.2$, caregiver's age, caregiver level of education, family number, child feeding per day, decision-making, number of ANC follow-up, the perceived severity of illness and early detection of disease were statistically associated with modern health-seeking behaviour.

In multiple logistic regression by using the backward elimination method, caregivers with age of $\geq 28$ years displayed more than 1.65 times health-seeking behaviour, than those with age of $\leq 27$ years (AOR: $1.65 ; 95 \%$ CI $[1.02,2.68]$ ). The odds that mothers with the educational level of secondary school and above were 0.44 times to have modern health-seeking behaviour than those with no education (AOR: 0.44; 95\% CI [0.23, 0.86]). The caregivers who feed their child $<8$ times per day seek 2.77 times more medical care than those who feed their child $\geq$ 8 times (AOR: 2.77; 95\% CI [1.75, 4.38]). Caregivers who perceive their child's illness as severe were two times higher to seek modern health care than mothers who perceive their child's illness as mild (AOR: 2; 95\% CI [1.07, 3.82]) (Table 4).

\section{Discussion}

The aim of this study was to assess the modern health careseeking behaviour of mothers and caregivers with children under the age of five years with childhood illness and to find out the associated factors. In this study, $76.2 \%$ of the caregivers sought modern health care when their child developed an illness. This finding is lower than the studies carried out in North West Ethiopia $84.4 \%,{ }^{19}$ Dangila town $82.1 \%,{ }^{13}$ Oromia region, Ethiopia $87 \%{ }^{20}$ and urban slum $90 \% .{ }^{17}$ The difference between these studies might be because of the difference in traditional practice and sociodemographics.

Modern health-seeking behaviour in this study is higher than the studies carried out in the rural Ensaro District, North Shoa Zone $59.9 \%{ }^{18}$ and Yemen $51.4 \% .^{10}$ This difference could be because of the availability of health posts in all selected Kebeles of our study area. The urban population could utilise health service more than the rural population. ${ }^{21}$ In our study, all the participants were from an urban dwelling. This could be explained by the fact that the urban population could have
TABLE 3: Mothers'/caregivers' modern health care-seeking behaviour from a child's illness to initiate care in Shire Town, North Ethiopia, $2018(n=504)$.

\begin{tabular}{|c|c|c|}
\hline Variables & Frequency & Percentage \\
\hline \multicolumn{3}{|l|}{ Illness of the child } \\
\hline Yes & 489 & 97.0 \\
\hline No & 15 & 3.0 \\
\hline \multicolumn{3}{|l|}{ Reported symptom (more options) ( $N=489$ ) } \\
\hline Cough & 261 & 53.4 \\
\hline Fever & 203 & 41.5 \\
\hline Diarrhoea & 128 & 26.2 \\
\hline Vomiting & 94 & 19.2 \\
\hline Eye problem & 57 & 11.7 \\
\hline Ear infection & 39 & 7.8 \\
\hline Jaundice & 23 & 4.7 \\
\hline Fast breathing & 21 & 4.3 \\
\hline Itching & 16 & 3.3 \\
\hline Cord swelling & 10 & 2.0 \\
\hline \multicolumn{3}{|c|}{ Was action taken to relieve the symptom? $(n=489)$} \\
\hline Yes & 472 & 96.5 \\
\hline No & 17 & 3.5 \\
\hline \multicolumn{3}{|l|}{ If yes what was the action $(n=472)$} \\
\hline Health institution & 384 & 76.2 \\
\hline Holy water & 22 & 4.4 \\
\hline Traditional healer & 4 & 0.79 \\
\hline Drug bought from a pharmacy & 61 & 12.1 \\
\hline Both traditional and holy water & 3 & 0.59 \\
\hline \multicolumn{3}{|l|}{ Modern health-seeking behaviour } \\
\hline Yes & 384 & 76.2 \\
\hline No & 120 & 23.8 \\
\hline \multicolumn{3}{|l|}{ If no, why not an action is taken } \\
\hline Waiting time & 3 & 17.6 \\
\hline Cost of medical care & 7 & 41.2 \\
\hline Illness was mild & 5 & 29.4 \\
\hline Previous bad experience from professional & 2 & 11.76 \\
\hline \multicolumn{3}{|l|}{ Decision makers for medical treatment } \\
\hline Mother & 358 & 71.0 \\
\hline Out of mother & 146 & 29.0 \\
\hline \multicolumn{3}{|c|}{ Perception of a mother about the severity of illness } \\
\hline Mild & 236 & 46.9 \\
\hline Moderate & 192 & 38.0 \\
\hline Severe & 61 & 12.1 \\
\hline \multicolumn{3}{|l|}{ Know severity } \\
\hline By any symptom & 283 & 56.2 \\
\hline If the illness continuous long time & 135 & 26.8 \\
\hline Loss of apatite & 86 & 17.0 \\
\hline \multicolumn{3}{|l|}{ The onset of seeking health care $(n=504)$} \\
\hline One day & 170 & 33.7 \\
\hline Two days & 136 & 26.9 \\
\hline Three days & 95 & 18.8 \\
\hline$>3$ days & 103 & 20.4 \\
\hline \multicolumn{3}{|c|}{$\begin{array}{l}\text { Maternal perception on the cause of childhood illness }(n=504) \\
\text { (more option was possible) }\end{array}$} \\
\hline Eating contaminated food and water & 320 & 63.5 \\
\hline Microorganism & 110 & 21.8 \\
\hline Lack of food & 106 & 21.0 \\
\hline Teething & 124 & 24.6 \\
\hline Evil eye & 102 & 20.2 \\
\hline Curse of God & 124 & 24.6 \\
\hline
\end{tabular}

access to information and, therefore, the caregivers could tend to seek care from nearby health facilities when the illnesses worsened. The other possible reason might be related to the expansion of urban health extension programmes that create awareness about early health-seeking behaviour. 
TABLE 4: Factors that affect health-seeking behaviour among mothers having under-five children in the Shire town, Northwest Ethiopia, 2018.

\begin{tabular}{|c|c|c|c|c|c|c|c|c|}
\hline \multirow[t]{3}{*}{ Variables } & \multicolumn{4}{|c|}{ Health-seeking behaviour } & \multicolumn{2}{|c|}{ Crude } & \multicolumn{2}{|c|}{ Adjusted } \\
\hline & \multicolumn{2}{|c|}{ Yes } & \multicolumn{2}{|c|}{ No } & \multirow[t]{2}{*}{ OR } & \multirow[t]{2}{*}{$95 \% \mathrm{Cl}$} & \multirow[t]{2}{*}{ OR } & \multirow[t]{2}{*}{$95 \% \mathrm{Cl}$} \\
\hline & $N$ & $\%$ & $N$ & $\%$ & & & & \\
\hline \multicolumn{9}{|l|}{ Age of the caregivers } \\
\hline$\leq 27$ years & 168 & 81.2 & 39 & 18.8 & 1 & - & 1 & - \\
\hline$\geq 28$ years & 216 & 72.7 & 81 & 27.3 & 1.62 & $1.05,2.49$ & 1.75 & $1.07,2.87^{*}$ \\
\hline \multicolumn{9}{|l|}{ Level of education } \\
\hline No education & 39 & 65 & 21 & 35 & 1 & - & 1 & - \\
\hline Primary school & 122 & 73.1 & 45 & 26.9 & 2.22 & $1.21,4.08$ & 0.73 & $0.37,1.44$ \\
\hline Secondary and above & 223 & 80.5 & 54 & 19.5 & 152 & $0.97,2.4$ & 0.44 & $0.23,0.86 *$ \\
\hline \multicolumn{9}{|l|}{ Family number } \\
\hline$<5$ & 262 & 78.0 & 74 & 22.0 & 1.33 & $0.87,2$ & 1.06 & $0.62,1.82$ \\
\hline$\geq 5$ & 122 & 72.6 & 46 & 27.4 & 1 & - & 1 & - \\
\hline \multicolumn{9}{|l|}{ Child feed per day } \\
\hline$<8$ times & 107 & 63.3 & 62 & 36.7 & 2.78 & $1.81,4.22$ & 2.77 & $1.75,4.38$ \\
\hline$\geq 8$ times & 277 & 82.7 & 58 & 17.3 & 1 & - & 1 & - \\
\hline \multicolumn{9}{|l|}{ Decision-making } \\
\hline Mother & 279 & 77.9 & 79 & 22.1 & 1 & - & 1 & - \\
\hline Out of mother & 105 & 71.9 & 41 & 28.1 & 1.38 & $0.89,2.14$ & 0.76 & $0.45,1.27$ \\
\hline \multicolumn{9}{|l|}{ Number of ANC visit } \\
\hline$<4$ times & 103 & 70.1 & 44 & 29.9 & 1.58 & $1.02,2.44$ & 1.35 & $0.82,2.20$ \\
\hline$\geq 4$ times & 281 & 78.7 & 76 & 21.3 & 1 & - & 1 & - \\
\hline \multicolumn{9}{|c|}{ Perceived severity of illness } \\
\hline Severe & 37 & 60.7 & 24 & 39.3 & 2.54 & $1.39,4.65$ & 2 & $1.07,3.82 *$ \\
\hline Moderate & 159 & 82.8 & 33 & 17.2 & 0.81 & $0.49,1.33$ & 0.88 & $0.53,1.48$ \\
\hline Mild & 188 & 79.7 & 48 & 20.3 & 1 & - & 1 & - \\
\hline \multicolumn{9}{|c|}{ Early detection of disease is important } \\
\hline Yes & 320 & 77.7 & 92 & 22.3 & 1.5 & $0.92,2.51$ & 0.72 & $0.4,1.28$ \\
\hline No & 64 & 69.6 & 28 & 30.4 & 1 & - & 1 & - \\
\hline
\end{tabular}

ANC, antenatal care; $\mathrm{OR}$, Odds ratio; $\mathrm{Cl}$, confidence interval.

$*$, statically significant at $p$-value of $<0.05$.

The age of a caregiver is one predictor of modern health care-seeking behaviour. In our study, caregivers aged $\geq 28$ years were 1.65 times more likely to have modern healthseeking behaviour than those aged $\leq 27$ years. This is consistent the study carried out in Dangila town ${ }^{13}$ North West Ethiopia ${ }^{19}$ and in Nigeria. ${ }^{22}$ As the age of mother increases, their experience increases, which helps them to easily identify the common childhood illness and seek better medical care.

It is obvious that higher level of caregiver's school education yields good modern health-seeking behaviour. School education could increase the mother's knowledge about common health problems, and healthy habits. In contrast to this idea, in our study, the odds of modern health-seeking behaviour among caretakers in secondary school and above the educational level were $66 \%$ less likely to seek medical care than non-educated ones. This is inconsistent with the study carried out in Yemen. ${ }^{10}$ This might be because of the dwelling similarity among the caregivers. As all the respondents in our study were from the urban dwelling.

Our finding revealed that the caregivers who feed $<8$ times a day were three times more likely to seek medical care than those who feed $\geq 8$ times. This could make the mothers/ caregivers aware that insufficient feeding could affect the child's health; therefore, the mothers/caregivers could seek modern health care in health institutions timely.
In this study caregivers perceiving of illness as severe were strongly associated to seek medical care. In the current study, mothers who perceived illness as severe were two times more likely to seek medical care than those who perceive the illness as mild. This finding is similar to studies carried out in Dangilia, ${ }^{13}$ Sierra Leon, ${ }^{23}$ Nigeria, ${ }^{24}$ a systemic review performed in developing countries, ${ }^{14}$ in Yemen ${ }^{10}$ and Kenya. ${ }^{14}$ This could be because the more severe episodes of illness might increase the likelihood of visiting a health service. This might be because of the mother's belief that the illness will improve by itself and she will wait until her child might show another symptom. Then this may put the children at risk of severe illness. This could be owing to the fact that 334 (66.3\%) of mothers / caregivers bring their child after two days onset of the symptom.

\section{Conclusion}

The overall modern health-seeking behaviour of mothers who have children under the age of five years were $76.2 \%$. Age of the mother 28 years and above, who fed her child < 8 times per day and perceived the severity of illness were the significant factors for health-seeking. The health care provider should be aware that any illness in childhood could affect the child. Therefore, health care services should be strengthened at the community level by introducing all the new mothers to the urban health extension workers. These health workers should increase awareness among mothers/caregivers regarding the symptoms of illness and timely care-seeking. 


\section{Acknowledgements}

The authors would like to thank all study participants and data collectors for their contribution in the success of their work.

\section{Competing interests}

The authors declare that they have no financial or personal relationships that may have inappropriately influenced them in writing this article.

\section{Authors' contributions}

G.T.W. conceived and designed the study, analysed the data and wrote the manuscript. G.T.W., T.M.Z. and T.T.A. were involved in data analysis, drafting of the manuscript and advising the whole research paper and also were involved in the interpretation of the data and contributed to manuscript preparation. H.T.A. was involved in manuscript preparation, data manipulation, methodology, data entry and analyses. T.M.Z. was involved in data analysis, drafting of the manuscript and advising the whole research paper. Similarly, all authors have read and approved the final version of the manuscript.

\section{Funding information}

This research received no specific grant from any funding agency in the public, commercial or not-for-profit sectors.

\section{Data availability statement}

Data sharing is not applicable to this article as no new data were created or analysed in this study.

\section{Disclaimer}

The views and opinions expressed in this article are those of the authors and do not necessarily reflect the official policy or position of any affiliated agency of the authors.

\section{References}

1. Bahrami MA, Atashbahar O, Shokohifar M, et al. Developing a valid tool of treatment seeking behaviour survey for Iran. J Novel Appl Sci. 2014;3(6):651-660.

2. Olenja J. Editorial health seeking behaviour in context. East Afr Med J. 2003; 80(2):61-62. http://doi.org/10.4314/eamj.v80i2.8689
3. World Health Organization. Constitution of WHO: Principles. Viitattu: WHO; 2017, p. 5.

4. Anyanwu FC, Okeke SR. Healthcare, care provider and client satisfaction: Transforming healthcare delivery system for improved healthcare seekin behaviour. J Modern Edu Rev. 2014;4(10):846-853. https://doi.org/10.15341/ jmer(2155-7993)/10.04.2014/014

5. World Health Organization. World health statistics 2016: Monitoring health for the SDGs sustainable development goals. Geneva: World Health Organization; 2016.

6. WHO. Children: Reducing mortality. Fact Sheet No 178. Geneva: WHO; 2013.

7. Ethiopia, F.D.R.O. Ethiopia demographic and health survey. Ethiopia: Central Statistical Agency, Addis Ababa; 2016

8. Sriram S, Soni $\mathrm{P}$, Thanvi $\mathrm{R}$, et al. Knowledge, attitude and practices of mothers regarding infant feeding practices. Natl J Comm Med. 2013;3(2):147-150.

9. Noordam AC, Carvajal-Velez L, Sharkey AB, et al. Care seeking behaviour for children with suspected pneumonia in countries in sub-Saharan Africa with high pneumonia mortality. PLoS One. 2015;10(2):e0117919. https://doi.org/10.1371/ journal.pone.0117919

10. Webair HH, Bin-Gouth AS. Factors affecting health seeking behaviour for common childhood illnesses in Yemen. Patient Prefer Adherence. 2013;2013(7):1129. https://doi.org/10.2147/PPA.S51124

11. Wardlaw T, You D, Hug L, et al. UNICEF Report: Enormous progress in child survival but greater focus on newborns urgently needed. Reprod Health. 2014;11(1):82 https://doi.org/10.1186/1742-4755-11-82

12. Teerawichitchainan B, Phillips JF. Ethnic differentials in parental health seeking for childhood illness in Vietnam. Soc Sci Med. 2008;66(5):1118-1130.

13. Dagnew AB, Tewabe T, Murugan R. Level of modern healthcare seeking behaviours among mothers having under five children in Dangila town, north West Ethiopia, 2016: A cross sectional study. Italian J Pediatr. 2018;44(1):61.

14. Geldsetzer P, Williams TC, Kirolos A, et al. The recognition of and care seeking behaviour for childhood illness in developing countries: A systematic review. PLoS One. 2014;9(4):e93427. https://doi.org/10.1371/journal.pone.0093427

15. Kuruvilla S, Schweitzer J, Bishai D, et al. Success factors for reducing maternal and child mortality. Bull World Health Organ. 2014;92(7):533-544. https://doi. org/10.2471/BLT.14.138131

16. Awoke W. Prevalence of childhood illness and mothers'/caregivers' care seeking behaviour in Bahir Dar, Ethiopia: A descriptive community based cross sectional study. Open J Preven Med. 2013;3(02):155. https://doi.org/10.4236/ojpm.2013.32020

17. Mahejabin F, Parveen S, Ibrahim M. Mother's/care Giver's health seeking behaviour during childhood illness. Bangladesh J. 2014;7(1):5-15. https://doi. org/10.3329/pulse.v7i1.23232

18. Sisay S, Endalew G, Hadgu G. Assessment of mothers/care givers healthcare seeking behaviour for childhood illness in Rural Ensaro District, North Shoa Zone, Amhara Region, Ethiopia. Global Journal of Life Sciences and Biological Research. 2014;1(1):20-34.

19. Gelaw YA, Biks GA, Alene KA. Effect of residence on mothers' healthcare seekin behaviour for common childhood illness in Northwest Ethiopia: A community based comparative cross-sectional study. BMC Res Notes. 2014;7(1):705. https:// based comparative cross-sectional
doi.org/10.1186/1756-0500-7-705

20. Assefa T, Assefa T, Belachew T, Tegegn A, Deribew A. Mothers' healthcare seekin behaviour for childhood illnesses in Derra district, Northshoa zone, Oromia regional state, Ethiopia. Ethiopian J Health Sci. 2008;18(3):87-94.

21. Aweke A. Assessment of health care seeking behaviour at household level in Sodo Zuria Wereda, SNNPR, Southern Ethiopia. Ethiopia: Addis Ababa University; 2005.

22. Ajibade B, Amoo PO, Adeleke MA, et al. Determinants of mothers health seeking behaviour for their children in a Nigerian teaching hospital. J Nurs Health Sci. 2013;1(6):9-16.

23. Diaz T, George AS, Rao SR, et al. Healthcare seeking for diarrhoea, malaria and pneumonia among children in four poor rural districts in Sierra Leone in the context of free healthcare: Results of a cross-sectional survey. BMC Pub Health. 2013;13(1):157. https://doi.org/10.1186/1471-2458-13-157

24. Abdulraheem I, Parakoyi D. Factors affecting mothers' healthcare-seeking behaviour for childhood illnesses in a rural Nigerian setting. Early Child Dev Care. 2009;179(5):671-683. 